Human survival is dependent upon the delivery of critical ecosystem services, including renewable resources, and the continued effective functionality of the ecosystems that provide these services (MEA 2005). Modern

\section{The role of ruminants in reducing agriculture's carbon footprint in North America}

W.R. Teague, S. Apfelbaum, R. Lal, U.P. Kreuter, J. Rowntree, C.A. Davies, R. Conser, M. Rasmussen, J. Hatfield, T. Wang, F. Wang, and P. Byck

\begin{abstract}
Owing to the methane $\left(\mathrm{CH}_{4}\right)$ produced by rumen fermentation, ruminants are a source of greenhouse gas (GHG) and are perceived as a problem. We propose that with appropriate regenerative crop and grazing management, ruminants not only reduce overall GHG emissions, but also facilitate provision of essential ecosystem services, increase soil carbon (C) sequestration, and reduce environmental damage. We tested our hypothesis by examining biophysical impacts and the magnitude of all GHG emissions from key agricultural production activities, including comparisons of arable- and pastoral-based agroecosystems. Our assessment shows that globally, GHG emissions from domestic ruminants represent $11.6 \%$ $\left(1.58 \mathrm{Gt} \mathrm{C} \mathrm{y}^{-1}\right)$ of total anthropogenic emissions, while cropping and soil-associated emissions contribute $13.7 \%\left(1.86 \mathrm{Gt} \mathrm{C} \mathrm{y}^{-1}\right)$. The primary source is soil erosion $\left(1 \mathrm{Gt} \mathrm{C} \mathrm{y}^{-1}\right)$, which in the United States alone is estimated at $1.72 \mathrm{Gt}$ of soil $\mathrm{y}^{-1}$. Permanent cover of forage plants is highly effective in reducing soil erosion, and ruminants consuming only grazed forages under appropriate management result in more $\mathrm{C}$ sequestration than emissions. Incorporating forages and ruminants into regeneratively managed agroecosystems can elevate soil organic C, improve soil ecological function by minimizing the damage of tillage and inorganic fertilizers and biocides, and enhance biodiversity and wildlife habitat. We conclude that to ensure longterm sustainability and ecological resilience of agroecosystems, agricultural production should be guided by policies and regenerative management protocols that include ruminant grazing. Collectively, conservation agriculture supports ecologically healthy, resilient agroecosystems and simultaneously mitigates large quantities of anthropogenic GHG emissions.
\end{abstract}

Key words: carbon sequestration-conservation agriculture-ecosystem services-greenhouse gases - regenerative ecosystem management-soil erosion

\begin{abstract}
Grasslands and savanna ecosystems around the world coevolved with grazing ruminants and fire (Frank and McNaughton 2002). While many of these ecosystems have been converted to crop production, others are not suitable for production of commodities for direct human consumption owing to their climatic, edaphic, or topographic limitations. Rather, they can be used by people for food and fiber production only if the plant resources are consumed by domestic or wild grazing herbivores (Herrero and Thornton 2013). Domesticated animals, notably cattle but also sheep and goats in the most arid areas, are the basis for many pastoral cultures, which generally observe customs connecting them to livestock in ways that have supported their collective health and prosperity for
\end{abstract}

centuries (Herrero and Thornton 2013). With appropriate management, grazers can enhance critical ecosystem services (Janzen 2010; Teague et al. 2013)

Some scientists have suggested that reductions in global ruminant numbers could make a substantial contribution to climate change mitigation goals and yield important social and environmental cobenefits (Ripple et al. 2014), but the value of such an option must be assessed within the larger context of all agricultural practices and geographic situations. We need to consider the broad context of ruminants in semiarid to mesic pastoral and agricultural ecosystems and how management in these different circumstances can balance the need for agricultural products without destroying our natural resource base. technology has substantially elevated the material wealth of most people in developed nations, but at the expense of healthy ecosystems that provide the goods and services upon which human survival ultimately depends (IPCC 2013). Renewable natural resources must be used in ways that prevent their depletion and promote ecosystem resilience for self-replenishment.

To ensure long-term delivery of ecosystem services, policies and management protocols for agricultural production should (1) support ecologically healthy and resilient arable and pastoral ecosystems; (2) mitigate anthropogenic greenhouse gas (GHG) emissions; (3) address environmental, social, cultural, and economic complexity; and (4) avoid unintended consequences of production practices. Failure to address unintended consequences in agriculture has contributed to serious ecological problems, most notably

W. Richard Teague is a research ecologist at Texas A\&M Agrilife Research in Vernon, Texas, and Department of Ecosystem Science and Management, Texas A\&M University, College Station, Texas. Steve Apfelbaum is a consulting ecologist with Applied Ecological Services, Inc. in Brodhead, Wisconsin. Rattan Lal is a research scientist in the School of Environment and Natural Resources at The Ohio State University in Columbus, Ohio. Urs P. Kreuter is a socio-economist in the Department of Ecosystem Science and Management at Texas A\&M University, College Station, Texas. Jason Rowntree is a research scientist in the Department of Animal Science at Michigan State University in East Lansing, Michigan. Christian A. Davies is a research scientist with Shell International Exploration and Production Inc., Shell Technology Center Houston in Houston, Texas. Russ Conser is a consulting engineer for Regenov8 Advisors in Fulshear, Texas. Mark Rasmussen is director at the Leopold Center for Sustainable Agriculture at lowa State University, Ames, lowa. Jerry Hatfield is director at the National Laboratory for Agriculture and the Environment, USDA Agricultural Research Services (ARS) in Ames, lowa. Tong Wang is a resource economist at Texas A\&M Agrilife Research in Vernon, Texas. Fugui Wang is a modeler with Applied Ecological Services, Inc. in Brodhead, Wisconsin. Peter Byck is a professor at the Wrigley Globallnstitute of Sustainability and Cronkit School of Journalism at Arizona State University Tempe and Phoenix, Arizona. 
increased GHG emissions, soil carbon (C) loss, and topsoil loss.

The problems of many current tillage-based cropping and feedlot-based livestock production systems can be avoided by ecologically sensitive management of ruminants in mixed crop and grazing agroecosystems. The benefits could include increased $\mathrm{C}$ sequestration, improved soil nutrient cycling, increased soil stability, enhanced watershed function, increased production of healthy food, and enhanced biodiversity and wildlife habitat (Liebig et al. 2010; Delgado et al. 2011).

Our objective is to provide an analysis of the cost-benefit trade-offs between livestock and arable crop production within whole agroecosystems. We outline the magnitude of GHG emissions from key agricultural components and practices and discuss how domesticated ruminants can be used as a tool to facilitate the delivery of essential ecosystem services, notably soil C sequestration and GHG emission reduction. We propose that with appropriate regenerative crop and grazing management, ruminants facilitate the provision of essential ecosystem services, increase soil $\mathrm{C}$ sequestration, reduce GHG emissions, and reduce environmental damage caused by many current agricultural practices. We tested our hypothesis by examining biophysical impacts and the magnitude of all GHG emissions from key agricultural production activities from peer-reviewed journal sources. This included comparisons of arable- and pastoral-based agroecosystems.

\section{Methods}

We collected data from peer-reviewed literature to compare the relative contributions of GHG emissions from major agricultural sources (table 1). Global estimates were obtained for domestic ruminants, mainly cattle, and other livestock (Ripple et al. 2014) to compare with emissions from crop production, including tillage, fertilization, harvest, and transport (Vermeulen et al. 2012), and soil erosion (Lal 2003). This was followed by an examination of peer-reviewed literature for the different components of both arable- and pastoral-based agroecosystems to determine ways of reducing GHG emissions from these sources and decreasing negative ecosystem service impacts of current agricultural practices. Soil erosion was a large component of emissions, and different methods and practices for reducing erosion were examined. This included use of permanent land cover

\section{Table 1}

Estimates of global sources of greenhouse gas (GHG) emissions related to agricultural soil management including cropping practices, soil erosion compared to that of livestock (We present the mean of ranges reported in the references cited).

\begin{tabular}{|c|c|c|c|}
\hline Parameter & Gt $C y^{-1 *}$ & $\begin{array}{l}\text { Percentage of } \\
\text { human caused } \\
\text { emissions }(\%)\end{array}$ & Source \\
\hline Total human caused emissions & 13.57 & & Ripple et al. 2014 \\
\hline Cropping and fertilizer & 0.86 & 6.3 & Vermeulen et al. 2012 \\
\hline Farm and rangeland soil erosion & 1.00 & 7.4 & Lal 2003 \\
\hline Total soil management & 1.86 & 13.7 & \\
\hline Cattle & 1.27 & 9.4 & Ripple et al. 2014 \\
\hline Other ruminants & 0.31 & 2.3 & Ripple et al. 2014 \\
\hline Other livestock & 0.39 & 2.9 & Ripple et al. 2014 \\
\hline Total livestock production & 1.97 & 14.5 & \\
\hline
\end{tabular}

*1 Gigaton $(\mathrm{Gt})=10^{9}$ metric tons.

with forage plants and cover crops that usually include grazing ruminants to achieve ecosystem service and livelihood goals.

We consider how grazing ruminants can be managed to enhance the provision of essential ecosystem services, increase soil C sequestration, and reduce environmental damage caused by many current agricultural practices, and the degree to which they can concurrently reduce GHG emissions from agricultural ecosystems. We examined the impact of the GHG footprint of grass-fed and finished ruminants compared to being fed grain-based diets.

To illustrate the potential of using ruminants as grazers and conservation cropping practices in agroecosystems to reduce net GHG emissions, we examine different scenarios of land management in North America. Our first set of five scenarios (figure 1) compares current cropping and grazing practice GHG impacts with 50\% reduction in ruminants, and different percentages of grazing land managed with conservation (adaptive multipaddock [AMP]) grazing.

The second set of five scenarios (figure 2) compares current cropping and grazing practice GHG impacts with 50\% reduction in ruminants and different percentages of both conservation cropping and conservation grazing management using data from the literature review of Delgado et al. (2011) and Teague et al. (2011). The data for conservation cropping is taken from the literature reviews of Gattinger et al. (2012) and Aguilera et al. (2013), who document the benefits of using conservation cropping practices referred to in the section on emission sources from agriculture. These sources report the sequestration of extra $\mathrm{C}$ from regenerative management of between -2 and $-4 \mathrm{t} \mathrm{C} \mathrm{ha}^{-1} \mathrm{y}^{-1}(-0.89$ and -1.78 tn $\mathrm{C}$ $\mathrm{ac}^{-1} \mathrm{yr}^{-1}$ ) compared to current management alternatives so we calculate GHG emission mitigation by regenerative, conservation grazing and cropping at $-3 \mathrm{t} \mathrm{Cha} \mathrm{h}^{-1} \mathrm{y}^{-1}(-1.2$ tn $\mathrm{C} \mathrm{ac}^{-1} \mathrm{yr}^{-1}$; figures 1 and 2).

These hypothetical scenarios are speculative because of a paucity of data, but they do represent an inclusive assessment of possible terrestrial and atmospheric impacts resulting from key agricultural activities in North America, using published peer reviewed field data. Calculations and data sources for these scenarios are presented in table 2 .

\section{Discussion}

Emission Sources from Agriculture. Analysis of key elements in the food supply-chain lifecycle indicates that agriculture generates substantial amounts of GHG emissions (Vermeulen et al. 2012). This, along with other environmental damage caused by agriculture (MEA 2005), indicates that the production of food to meet global demand comes at considerable environmental and social cost. Since tillage-based farming began, most agricultural soils have lost 30\% to 75\% of their soil organic carbon (SOC), with industrial agriculture accelerating these losses (Delgado et al. 2011). In some areas, instead of increasing food yields, high input agriculture has led to a decrease in food production due to the environmentally deleterious effects on soils (Janzen 2010). It is important to note that anthropogenic sources of GHG emissions from intensive crop production are independent from ruminants and would be produced even if ruminant numbers were reduced because food from nonruminant 
sources would be needed to compensate for the diminished ruminant product supplies.

Globally, the GHG emissions from domestic ruminants represent $11.6 \%(1.58 \mathrm{Gt} \mathrm{C}$ $\mathrm{y}^{-1}$ ) of total anthropogenic emissions (table 1; Ripple et al. 2014; Vermeulen et al. 2012; Lal 2003). In contrast, soil-associated losses contribute $13.7 \%\left(1.86 \mathrm{Gt} \mathrm{C} \mathrm{y}^{-1}\right)$ of total anthropogenic emissions with $46 \%$ (0.86 Gt $\mathrm{C}^{-1}$ ) resulting from crop production inputs, including fertilizers, fuels, and pesticides, and $54 \%$ of the emissions $\left(1 \mathrm{Gt} \mathrm{C} \mathrm{y}^{-1}\right)$ from wind, water, and tillage erosion, and to a lesser extent erosion caused by inappropriate grazing practices. Based on these estimates and assuming no change in production practices, projected impacts of agricultural practices on GHG emissions are expected to increase as food production increases to meet the demands of a growing global population.

Soil erosion caused by current cropland management contributes directly to increasing GHG emissions (Lal 2003). In the United States, annual soil mass losses from crop and grazing land $\left(1.72 \mathrm{Gt}\right.$ soil $\mathrm{y}^{-1}$; Lal $2003)$ is three times greater than the combined yields from corn (Zea mays L.; 0.36

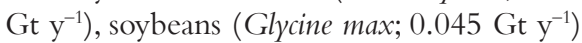
and hay (0.146 Gt $\mathrm{y}^{-1}$; USDA 2012). Unless measures are taken to reduce soil erosion, current agricultural practices are unsustainable and are greater sources of GHG emissions than ruminant livestock in these agroecosystems (table 1).

Additionally, common tillage practices and the application of inorganic fertilizers and biocides have reduced soil surface cover and decimated soil microbial communities that control $90 \%$ of soil ecosystem function. Collectively, these crop production inputs have contributed to the degradation of physical, chemical, and biological properties of soils (Bardgett and McAlister 1999; Leake et al.2004; Khan et al. 2007; Leigh et al. 2009; Mulvaney et al. 2009; Czarnecki et al. 2013; Kimble et al. 2007). Declining microbial communities result in reduction of nutrient concentrations and availability in the remaining soil (Delgado et al. 2011). The impact of these losses is exacerbated by excess amounts of nutrients applied (i.e., inorganic fertilizers) for 17 of the world's major crops (West et al. 2014).

Intensification of agriculture continues to increase surface water runoff, soil erosion, and siltation of reservoirs. Under the anaerobic conditions in anoxic sediment deposits, emissions of methane $\left(\mathrm{CH}_{4}\right)$, nitrous oxide
$\left(\mathrm{N}_{2} \mathrm{O}\right)$, and ammonia $\left(\mathrm{NH}_{3}\right)$ from water bodies are $1 \pm 0.2 \mathrm{Gt} \mathrm{C} \mathrm{y}^{-1}$ (Lal 2003) and approach emissions from cattle at $1.27 \mathrm{Gt} \mathrm{C}$ $\mathrm{y}^{-1}$ (Herrero and Thornton 2013). The $\mathrm{N}_{2} \mathrm{O}$ and $\mathrm{CH}_{4}$ emissions emitted from the disturbance of continued tillage and erosion of SOC from clay and silt clay loam soils have been one of the primary sources of GHG emissions, accounting for a large percentage of all GHG emissions produced by modern civilization (Lal 2003, 2004).

In addition to the negative impacts of the increasingly industrialized production of crops, there has also been considerable degradation of rangelands, which comprise approximately $40 \%$ of the global terrestrial area (excluding Greenland and Antarctica). As rangeland ecosystems constitute approximately $25 \%$ of potential C sequestration in global soils (Follett and Reed 2010), their degradation also contributes to elevated GHGs emissions, reduction of ecosystem services, and increased desertification.

Historically, many rangelands have been subjected to increasingly heavy continuous grazing (CG) by livestock. This management approach, which allows sustained access to plants by grazing ruminants without an opportunity for recovery between grazing events, has been documented as contributing to serious negative effects, such as depletion of root biomass and carbohydrate reserves in selectively grazed plants and reduction in aboveground biomass productivity. Other negative effects of poor grazing management include impoverished herbaceous plant communities, more bare ground, lower SOC reserves, and increased soil erosion and compaction (Janzen 2010; Teague et al. 2013). At landscape scales these changes have contributed to lower surface water infiltration, increased runoff and downstream flooding, and reductions in water quality (Janzen 2010; Teague et al. 2013). As with tillage agriculture, the sediments from eroded grassland soils also emit GHG when organic matter in sediments enters anaerobic waterways. As the health of the land declines, so too does the health of the livestock and people dependent on livestock.

Powerful reminders of the detrimental impacts of many current industrial cropping and grazing practices are the anoxic polluted lower reaches of the Mississippi, the dead anoxic zone in the Gulf of Mexico, and the chronic demise of pollinators in North American cropping areas (Turner and
Rabalais 2003; MEA 2005). Viable alternatives to the damaging impacts of current agricultural management based on tillage and high inputs of fertilizers, pesticides, hormones, and medicines are offered by ecologically sensitive regenerative management with low inputs that build rather than destroy the biological base of living ecosystems (Pimentel et al. 2005).

Alternative management options to reduce or eliminate negative impacts of many current agricultural practices have been outlined by Delgado et al. (2011), Gattinger et al. (2012), and Aguilera et al. (2013). These include (1) changing plow tillage to no-till (NT) cropping and using precision agriculture to moderate the rate and timing of application of agrochemicals and water (Hatfield and Venterea 2014); (2) diversifying annual cropping systems to include legumes, perennial crops, and forages in rotations; (3) using cover crops in conjunction with row crops; (4) reintegrating grazing animals back into cropping systems; (5) using organic soil amendments, such as cover crops, manure, and biofertilizers; (6) reducing nitrogen (N)-fertilizer use, changing the type of fertilizer used (e.g., legumes, controlled-release, and nanoenhanced fertilizers), and using nitrification inhibitors; (7) applying biotic fertilizer formulations that feed the soil microbial systems and improve mycorrhizal function, reducing $\mathrm{N}$ and phosphorus $(\mathrm{P})$ runoff and ground water losses (Hatfield and Walthall 2014); and (8) improving grazing management, converting marginal and degraded cropland to permanent pasture and forests, and restoring wetlands.

Livestock as Part of the Solution. Ruminants grazing in rangeland or cultivated forage agroecosystems are beneficial when they are appropriately managed (Delgado et al. 2011; Teague et al. 2013). Grazing ungulates play key ecological roles in grasslands and savannas, and can contribute positively to numerous ecosystem services. Beneficial effects could include increased water infiltration, improved water catchment, greater biodiversity, increased ecosystem stability and resilience, and improved $\mathrm{C}$ sequestration; all of which can help mitigate GHG emissions (DeRamus et al. 2003). When domestic ruminants are managed in a way that restores and enhances grassland ecosystem function, increased $\mathrm{C}$ stocks in the soil will lead to larger and more diverse populations of soil microbes, which in turn leads 
to greater $\mathrm{C}$ sequestration, including $\mathrm{CH}_{4}$ oxidation (Bardgett and McAlister 1999; Teague et al. 2013; Jamali et al. 2014). With livestock management focused on building soil health, grazing animals can create $\mathrm{C}$ negative budgets, with more $\mathrm{C}$ entering the soil than is emitted indirectly or via ruminant emissions (Janzen 2010).

Combining crop rotation with livestock grazing can be particularly effective at enhancing soil function and health (Delgado et al. 2011). Crop production can be managed to maintain permanent ground cover through the rotation of forage and row crop mixes, including cover crops, and legumes to increase soil fertility by fixing N. Grazing livestock can accelerate nutrient cycling through the consumption and decomposition of residual aboveground biomass. For example, sowing winter crops into permanent summer growing pastures and using crop rotation systems with forage crops and grazing animals have been shown to significantly reduce the damaging effects of many current arable land management practices, including soil erosion, loss of SOC, and elevated GHG emissions, especially where soil erosion potential is moderate to high (Delgado et al. 2011).

Achieving the same soil health benefits in pasture and rangeland-based livestock production systems as in mixed rotational cropping-livestock systems typically requires a change in land management practice. Ruminant production entirely from pastures has been achieved most effectively, efficiently, and economically using appropriate regenerative grazing management (Delgado et al. 2011; Janzen 2010; Teague et al. 2011, 2013; Gerrish 2004). Thus the most significant improvements can be achieved when erosion-prone cropping systems are replaced by permanent pastures maintained under improved grazing management.

On rangelands, use of regenerative AMP grazing management has been demonstrated globally to be capable of reversing degradation processes associated with the widespread practice of CG at high stocking rates (Teague et al.2011,2013; Gerrish 2004). Regenerative management uses a goal-oriented, proactive, multipaddock grazing strategy focused on restoring the ecological function and productivity of degraded grasslands. The approach uses short periods of grazing in any given area and proactively adjusts postgrazing forage residuals, recovery periods, and other

\section{Figure 1}

Hypothetical North American net greenhouse gas (GHG) emission scenarios for: (1) current agriculture; (2) current agriculture with $50 \%$ current ruminants; ( 3 ) current cropping and $25 \%$ regenerative adaptive multipaddock (AMP) conservation grazing with current numbers of ruminants; (4) current cropping and 50\% AMP grazing with current numbers of ruminants; and (5) current cropping and $100 \%$ AMP grazing with current numbers of ruminants.

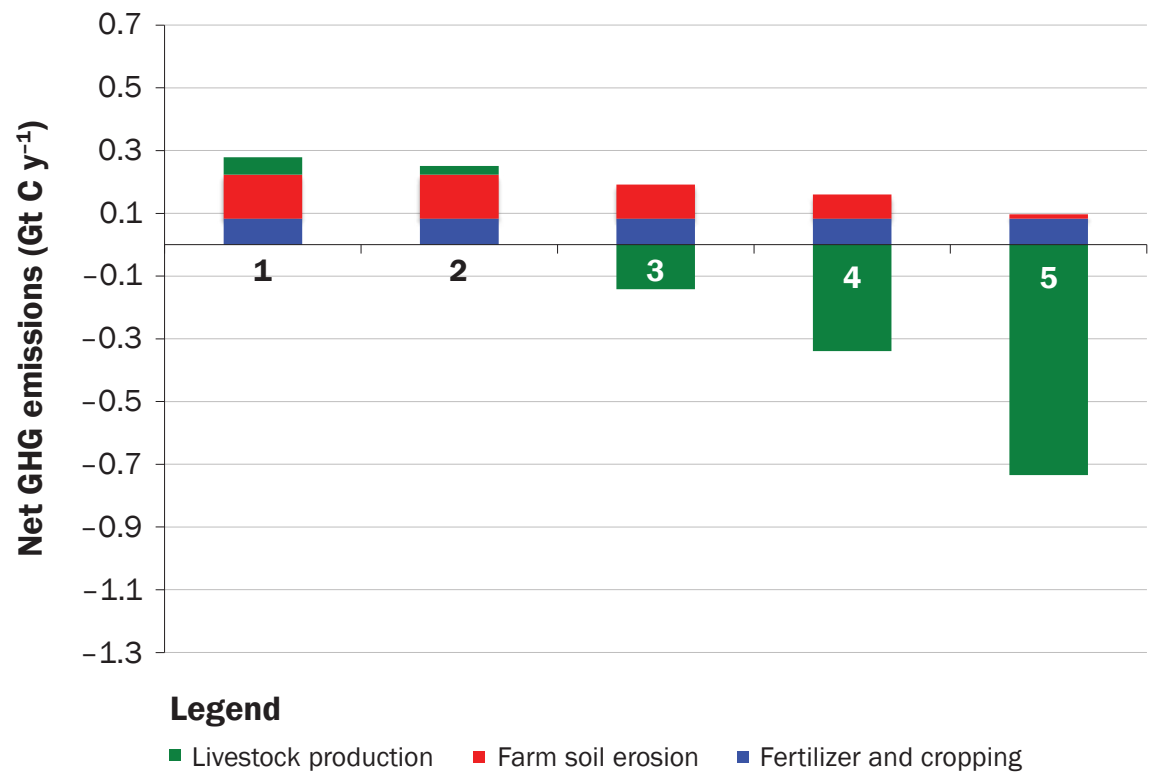

Figure 2

Hypothetical North American net greenhouse gas (GHG) emission scenarios for: (1) current agriculture; (2) current agriculture with $50 \%$ current ruminants; (3) $25 \%$ conservation cropping and adaptive multipaddock (AMP) grazing with current numbers of ruminants; (4) $50 \%$ conservation cropping and AMP grazing with current numbers of ruminants; and (5) $100 \%$ conservation cropping and AMP grazing with current numbers of ruminants.

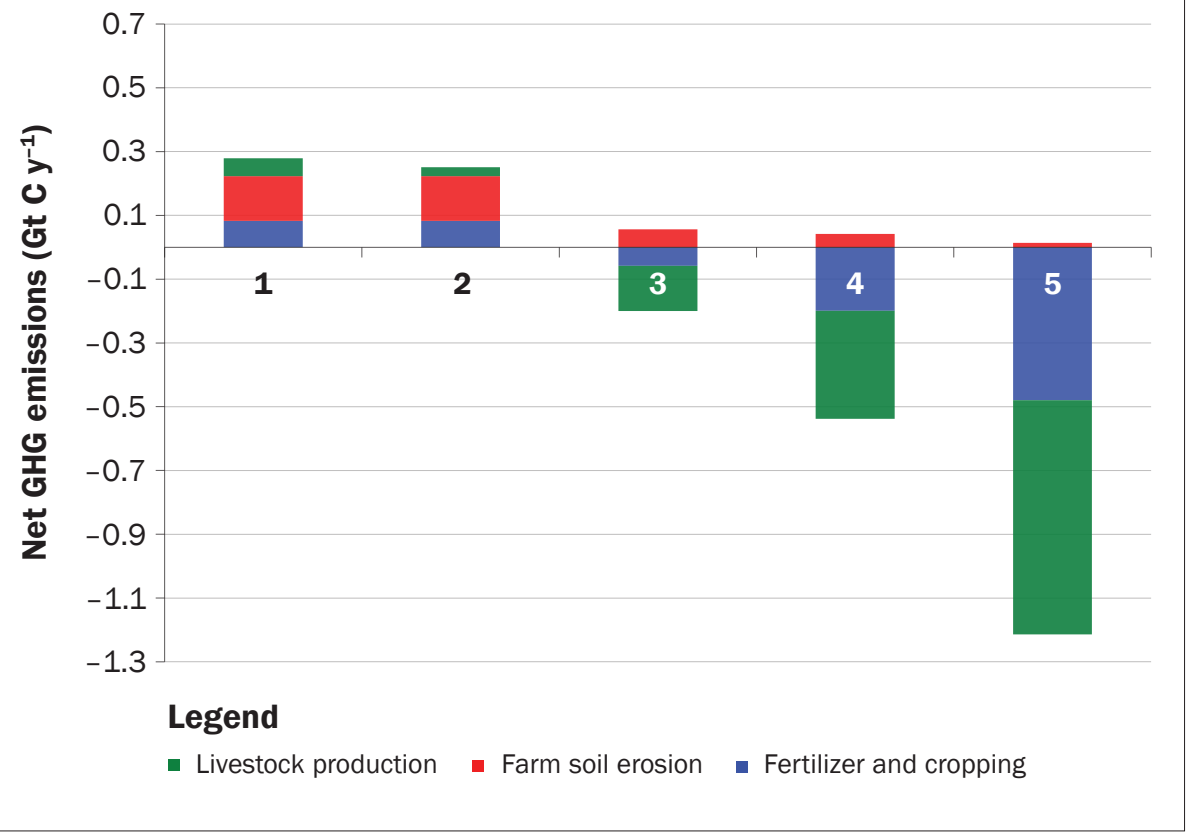




\section{Table 2}

Details of estimates to determine North American greenhouse gas (GHG) emissions due to current cropping and grazing management, current cropping with reduced ruminants compared to using conservation cropping and regenerative adaptive multipaddock (AMP) grazing with current levels of ruminants used for figure 1 and figure 2 (scenarios 3 through 5 assume stated percentage of land under conservation cropping and AMP grazing with the remainder applying usual practices.).

\begin{tabular}{|c|c|c|c|c|c|}
\hline \multirow[b]{2}{*}{ Parameter } & \multicolumn{5}{|c|}{ Scenario (Gt C y $\left.\mathbf{y}^{-1}\right)$} \\
\hline & 1 & 2 & 3 & 4 & 5 \\
\hline \multicolumn{6}{|l|}{ Current cropping with AMP grazing } \\
\hline Crop production (USEPA 2006; O’Mara, 2011) & 0.083 & 0.083 & 0.083 & 0.083 & 0.083 \\
\hline Soil erosion* (Lal 2003) & 0.14 & 0.14 & 0.109 & 0.077 & 0.014 \\
\hline Livestock production (Ripple et al. 2014; Vermeulen et al. 2012) & 0.056 & 0.028 & 0.056 & 0.056 & 0.056 \\
\hline AMP grazing $†$ & 0 & 0 & -0.198 & -0.395 & -0.790 \\
\hline Net livestock $\dagger$ & 0.056 & 0.028 & -0.142 & -0.339 & -0.734 \\
\hline Total & 0.279 & 0.251 & -0.050 & -0.179 & -0.637 \\
\hline \multicolumn{6}{|l|}{ Conservation cropping with AMP grazing } \\
\hline Crop production $\ddagger$ (Gattinger et al. 2012; Aguilera et al. 2013) & 0.083 & 0.083 & -0.058 & -0.199 & -0.480 \\
\hline Soil erosion* (Lal 2003) & 0.14 & 0.14 & 0.056 & 0.042 & 0.014 \\
\hline Livestock production (Ripple et al. 2014; Vermeulen et al. 2012) & 0.056 & 0.028 & 0.056 & 0.056 & 0.056 \\
\hline AMP grazing $†$ & 0 & 0 & -0.198 & -0.395 & -0.790 \\
\hline Net livestock & 0.056 & 0.028 & -0.142 & -0.339 & -0.734 \\
\hline Total & 0.279 & 0.251 & -0.143 & -0.496 & -1.200 \\
\hline
\end{tabular}

*Soil erosion was considered to be $50 \%$ less with both AMP grazing and conservation cropping.

†-3 t C ha-1 $\mathrm{y}^{-1}$ (Delgado et al. 2011; Teague et al. 2011) for $263 \times 10^{6}$ ha grazing lands (UN FAO 2011).

‡ Conservation cropping at -3 t C ha ${ }^{-1} \mathrm{y}^{-1}$ (Gattinger et al. 2012; Aguilera et al. 2013) for $160 \times 10^{6}$ ha (UN FAO 2011).

management elements as biophysical conditions change (Teague et al. 2013; Gerrish 2004; Butterfield et al. 2006). Regenerative AMP grazing has been successfully applied in areas with annual rainfall ranging from 250 to $1,500 \mathrm{~mm}$ (9.8 to $59 \mathrm{in})$ and the best regeneration, ecosystem service and production results (Teague et al. 2011, 2013) have been achieved using regenerative management protocols (Butterfield et al. 2006).

Such grazing management has resulted in increased forage productivity, restoration of preferred herbaceous species that were harmed by previous grazing practices, and increased SOC, soil fertility, water holding capacity, and economic profitability for ranchers (Teague et al. 2011, 2013). Data presented by Teague et al. (2011) of "across the fence" comparisons in southern tallgrass prairie in Texas, where AMP was applied to areas previously degraded through prolonged CG, enable us to calculate an average of $3 \mathrm{t} \mathrm{C} \mathrm{ha}^{-1} \mathrm{y}^{-1}\left(1.2 \mathrm{tn} \mathrm{C} \mathrm{ac}^{-1} \mathrm{yr}^{-1}\right)$ more $\mathrm{C}$ sequestration in the top $90 \mathrm{~cm}$ (35.4 in) of soil over a decade in AMP grazing compared to commonly practiced heavy CG (table 2). Research has also shown that AMP grazing management led to higher herbaceous plant cover and plant productivity; reduced bare ground, erosion, and nonlivestock related GHG emissions; and improved hydrological processes (DeRamus et al. 2003). Where regenerative grazing has been practiced in semiarid and arid lands for some time, ephemeral streams have reperennialized and biodiversity has recovered to varying degrees. Additionally, soil-building cool-season and warm-season grasses, $\mathrm{N}$ fixing native leguminous plant species, and even pollinators have increased (National Research Council 2002).

The paleo record also provides evidence that regenerative human management of grassland agroecosystems can create a large $\mathrm{C}$ sink to curb anthropogenic GHG emissions (Retallack 2013). The coevolution of grass and grazers over the last 40 million years caused the global expansion of C-rich soils in semiarid to semihumid grassland regions covering approximately $40 \%$ of the global land area. This likely induced global cooling, decreased precipitation, and decreased carbon dioxide $\left(\mathrm{CO}_{2}\right)$ during the Oligocene, Miocene, and Quaternary periods (Retallack 2013). Soil changes are believed to have been caused by the large migratory, socially organized, ungulate herds constantly moving and avoiding fouled grazing sites, seeking water and nutrients, and responding to predation, fire, herding, and hunting (Frank and McNaughton 2002; Teague et al. 2013; Butterfield et al. 2006). Grazing seldom lasted long before the animals moved to new feeding grounds, leaving the old grounds with extended periods of recov- ery from defoliation. The coevolved soil microbes and fauna rapidly recycled nutrients and enhanced soil structure to result in more fertile, crumb-structured soils with better infiltration and water holding capacities that enhanced soil C levels (Teague et al. 2013; Retallack 2013). In areas such as Australia where sod grasses and native ungulates did not coevolve, very few C-rich soils developed, compared to areas such as Africa and North America where such coevolution did occur. However, after the settlement of Australia by Europeans and the introduction of sheep and cattle and associated pasture improvements with introduced legumes, earthworms, and dung beetles, C-rich soils have been created where rainfall permitted. Similarly, improved regenerative grassland management in Australia has been shown to increase soil C and enhance ecological function (Retallack 2013).

Regarding net ruminant-based enteric $\mathrm{CH}_{4}$ emissions, the $\mathrm{C}$ footprint of beef cattle production solely from grassland is exceeded by the amount of $\mathrm{C}$ sequestered by the grasses and soil upon which they graze. Data from the Northern Plains (Liebig et al. 2010) report modest annual SOC sequestration rates with conventional $\mathrm{CG}$ management $\left(-0.618 \mathrm{t} \mathrm{CO}_{\text {2equiv }} \mathrm{ha}^{-1} \mathrm{y}^{-1}\right.$ for heavy stocking and $-0.783+\mathrm{CO}_{\text {2equiv }} \mathrm{ha}^{-1} \mathrm{y}^{-1}$ for moderate stocking $\left[-0.250\right.$ tn $\mathrm{CO}_{\text {2equiv }}$ 
$\mathrm{ac}^{-1} \mathrm{yr}^{-1}$ for heavy stocking and $-0.317 \mathrm{tn}$ $\mathrm{CO}_{\text {2equiv }} \mathrm{ac}^{-1} \mathrm{yr}^{-1}$ for moderate stocking]). Overall enteric $\mathrm{CH}_{4}$ was reported to be 0.484 and $0.176 \mathrm{t} \mathrm{CO}_{\text {2equiv }} \mathrm{ha}^{-1} \mathrm{y}^{-1}(0.196$ and 0.0713 tn $\mathrm{CO}_{\text {2equiv }} \mathrm{ac}^{-1} \mathrm{yr}^{-1}$ ), respectively, indicating a negative GHG balance for both conventionally grazed systems. However, as noted previously, improved AMP grazing management can result in an average SOC sequestration rate of $11 \mathrm{t} \mathrm{CO}_{2 \text { equiv }} \mathrm{ha}^{-1} \mathrm{y}^{-1}(3 \mathrm{t}$ $\mathrm{C} \mathrm{ha}^{-1} \mathrm{y}^{-1}\left[1.2\right.$ tn $\left.\mathrm{C} \mathrm{ac}^{-1} \mathrm{yr}^{-1}\right]$ ) more than that of heavily stocked CG (Teague et al. 2011). With respect to global warming potential, SOC is the largest determinant in the $\mathrm{C}$ footprint of beef production from a forage base managed to maximize $\mathrm{C}$ sequestration.

Most cattle produced in developed countries from conventional, continuously grazed rangelands and forage-based grazing systems are finished for the marketplace on high starch, grain-based feeds. Proponents of this finishing method claim that, compared to grass-finished beef production, intensification of production through the use of grain-based feeds results in lower GHG emissions per kilogram beef produced because it reduces the overall production time to slaughter and enteric fermentation during this time (Capper 2012). However, this claim does not take into consideration the full GHG emissions associated with the production of grain-based feeds and soil erosion. Not accounting for substantial GHG emissions resulting from crop production greatly underestimates $\mathrm{GHG}$ output from feedlot-based beef production (table 1). However, should grain production be converted to regenerative practices, this would diminish GHG production substantially (Gattinger et al. 2012; Aguilera et al. 2013). Consequently, suitable modification of agroecosystem production systems and conversion to regenerative cropping and AMP-based grass-finished livestock would also increase the provisioning of other important ecological benefits (DeRamus et al. 2003) as outlined in the alternative scenarios below.

Producing grass-finished beef in AMP management schemes obviates the need for finishing animals on grain-based diets. This switch reduces the $\mathrm{C}$ footprint of ruminant production because of the elimination of soil GHG emissions resulting from grain production and associated soil erosion. Therefore, beef production without grain inputs or grain from regenerative cropping has the potential to reduce fossil fuel inputs, $G H G$ emissions, and soil erosion, while improving health and resilience of the agroecological system as well as human health (Daly et al. 2010). There has been a rapid increase in demand for grass-fed beef (Herrero and Thornton 2013) as many beef consumers recognize that grass-fed and grass-finished beef is better for both their health and the environment. In addition, if crop production currently used for animal feed and other uses, such as biofuels, were instead used for human food products, supplies would be increased by $70 \%$, thus providing sufficient resources for an additional four billion people (West et al. 2014)

Therefore, widespread conversion of livestock-purposed cropland to a rotation with perennial pasture or rangeland, such as the integrated crop and pasture systems associated with Australian ley farming systems (Carberry et al. 1996), would be the most advantageous option to reduce overall crop and livestock-associated GHG emissions.

Consequently, we propose that rather than reducing ruminant livestock to mitigate climate change, producers should be encouraged to replace their current unsustainable crop and livestock practices with regenerative management practices. In both cropping and grazing systems, soil management is the key to optimizing ecological function and reversing degradation caused by previous management. If we do not manage to reverse soil functional degradation, the damaging effects on soils will decrease food production potential, as noted by Janzen (2010). From research and studying successful conservation farmers, soil ecological function is maintained by using perennial plants rather than annuals, managing for the most productive plants, using diverse species mixes and cover crops, leaving plant residue, eliminating tillage damage, keeping the soil covered with plant material and minimizing bare ground, using organic soil amendments, reducing $\mathrm{N}$ fertilizer use, and growing plants for the maximum number of days each year (Delgado et al. 2011; Teague et al. 2011; Gattinger et al. 2012; Aguilera et al. 2013).

Alternative Net Greenhouse Gas Emission Scenarios. In figure 1 we postulate five scenarios for land management changes to reduce and ultimately reverse GHG emissions associated with current cropping practices while adopting regenerative AMP grazing practices:
- Scenario 1 represents the estimated total C emissions from soil erosion loss, current tillage and fertilizer practices for crop production, corn-finished livestock production, and current CG management. It most closely resembles the substantial $\mathrm{C}$ footprint of the current agricultural practices.

- Scenario 2 represents the reduction of ruminants by $50 \%$ from the current numbers as proposed by Ripple et al. (2014). It has only a modest impact on total C emissions from all agricultural activities.

- Scenarios 3, 4, and 5 represent adoptions of best conservation management practices in grazing on $25 \%, 50 \%$, and $100 \%$, respectively, of land used in North America for livestock production. These conservation management practices include grass-fed and grass-finished beef production using AMP grazing management.

Similarly, in figure 2 we postulate five scenarios for land management changes to reduce and ultimately reverse GHG emissions associated with both regenerative conservation cropping practices and regenerative AMP grazing practices:

- Scenarios 1 and 2 in figure 2 are the same as in figure 1.

- Scenarios 3, 4, and 5 represent adoptions of best conservation management practices in both cropping and grazing on $25 \%$, $50 \%$, and $100 \%$, respectively, of land used in North America for crop and livestock production. These conservation management practices include zero till and crop rotations with minimal inorganic fertilizer use in crop production, and grass-fed and grass-finished beef production using AMP grazing management.

The application of these regenerative conservation practices in crop and livestock production systems to just $25 \%$ of the land they occupy results in substantially less net $\mathrm{C}$ emission than reducing livestock by $50 \%$. Applying them to greater portions of agricultural production land results in increasingly negative net $\mathrm{C}$ emissions with application to all agricultural land, potentially providing a significant $\mathrm{C}$ sink to offset nonagricultural emissions.

These scenarios provide a set of testable hypotheses that could direct future longterm (at least 10 years) systems-based research at the operating scale. Figure 3 presents a schematic outlining the scenarios depicted in figure 2. To date such research has been lacking due to funding and logistical constraints. These constraints have led to a plethora of 
short-term and small-scale crop and livestock production research, the results of which frequently bear no resemblance to the performance of best management practices applied across the whole-systems operating scale (Teague et al. 2013; Van der Ploeg et al. 2006). The principle reason for this disconnect is the lack of capacity for short-term and small-scale research to address interactions at the systems level; land management lag effects; and both spatial and temporal heterogeneity of soils, vegetation, and livestock impact and precipitation patterns at operational scales.

Development and Adoption of Regenerative Management. To effect management changes that will lead to a more sustainable future it is vital to create government agricultural policies that encourage the adoption of regenerative GHG neutral, or possibly GHG negative, agricultural practices. Such policy changes should reward producers for adopting and maintaining environmentally sustainable management practices for both crop and livestock production and discourage the use of land management practices that require high energy inputs and irrigation, and that degrade soils, reduce biodiversity, and increase GHG emissions.

At a minimum, policy changes should encourage farmers to implement no-till agriculture, more diverse crop rotations, more perennial forages, greater biodiversity in the form of cover crops between rotations, regenerative grazing management, and minimized nongrazing feeding of ruminants. Such policies would lead to an expansion of mixed agronomic systems that facilitate the reintroduction of grazing animals as an element of integrated food production versus the government-incentivized monoculture systems that are leading to the environmental damage outlined in this document.

To operationalize such policies, it is equally vital that leaders in farming and ranching communities across the world actively participate in developing workable solutions and adaptive practices for food production ecologically suited to local biophysical conditions (Herrero and Thornton 2013; Janzen 2010). Leading environmentally conscious farm and ranch managers are demonstrating how it is possible to achieve desired environmental goals, while simultaneously improving livelihoods.

Knowledge gained from reductionist science does not translate automatically into producing desirable results from crop or grazing agroecosystems, especially at watershed scales or across regions (Teague et al. 2013; Van der Ploeg et al. 2006). To be meaningful, small-scale reductionist research should be subsumed within complementary whole-systems research. To achieve this, it is imperative to work in collaboration with farmers and ranchers who obtain superior economic returns in different ecological and cultural settings while simultaneously improving the biophysical conditions of their environments (Van der Ploeg et al. 2006). Finally, working to educate drivers of change, from policymakers to the farming community, is essential to overcome the complexity associated with GHG emissions and overall impacts of ruminant livestock and crop production.

\section{Conclusions}

Soil is a depletable resource, but production of food for human consumption does not have to deplete the soil. Cropping and grazing practices that build SOC levels and soil microbial communities and functions, and that minimize soil erosion can result in soils being a net sink for GHGs rather than a major source of GHGs, as is currently the case. Effective soil management provides the greatest potential for achieving sustainable use of agricultural land under a rapidly changing climate. Ruminant livestock are an important tool for achieving sustainable agriculture. With appropriate grazing management, ruminant livestock can increase C sequestered in the soil to more than offset their GHG emissions, and can support and improve other essential ecosystem services for local populations. Affected ecosystem services include water infiltration, nutrient cycling, soil formation, C sequestration, biodiversity, and wildlife habitat. Our assessment suggests that increasing SOC globally within food production systems will reduce the $\mathrm{C}$ footprint of agriculture much more than reducing domesticated ruminant numbers in an effort to reduce enteric GHG emissions. The simultaneous increase in production of agricultural goods indicates that integrating livestock into mixed agricultural systems and grazing management to increase SOC, biodiversity, and soil quality would enhance resilience of soil and agroecosystems against climate change and extreme events.

A primary challenge to the increasing global demand for food is how to increase the scale of adoption of land management practices documented to have a positive effect on soil health. It is essential that scientists partner with environmentally progressive managers at sufficiently large scales to convert experimental data on managed landscapes into sound environmental, social, and economic results that will provide regional and global benefits. Rather than reducing ruminants and encouraging destructive agricultural land use by providing price subsidies and other subsidies, rewarding regenerative agricultural practices that focus on increasing soil $\mathrm{C}$ and that lead to greater adoption by land managers is essential to creating a robust, resilient, and regenerative global food production system.

\section{Acknowledgements}

We thank Doug Karlen (supervisory research soil scientist, National Laboratory for Agriculture and the Environment, USDA Agricultural Research Service, Ames, Iowa), John Kimble (director [retired] USDA Natural Resource Conservation Service-NSSC, Lincoln, Nebraska), Marcia DeLonge (scientist, Union of Concerned Scientists, Cambridge Massachusetts), and Henk Mooiweer (GameChanger leader at Shell and Adjunct Professor Invention and Innovation at Rice University, Shell Oil Company, Shell Technology Center Houston, Houston, Texas) for comments and inputs to earlier drafts of the manuscript.

\section{References}

Aguilera, E., L. Lassaletta, A. Gattingerd, and B.S. Gimeno. 2013. Managing soil carbon for climate change mitigation and adaptation in Mediterranean cropping systems: A meta-analysis. Agriculture Ecosystems and Environment 168:25-36.

Bardgett, R.D., and E. McAlister. 1999. The measurement of soil fungal: bacterial biomass ratios as an indicator of ecosystem self-regulation in temperate meadow grasslands. Biology and Fertility of Soil 29:282-290.

Butterfield, J., S. Bingham, and A. Savory. 2006. Holistic management: A new framework for decision making. Washington, DC: Island Press.

Capper, J.L. 2012. Is the grass always greener? Comparing the environmental impact of conventional, natural and grass-fed beef production systems. Animals 2:127-143.

Carberry, P.S., R.L. McCown, R.C. Muchow, J.P. Dimes, M.E. Probert, P.L. Poulton, and N.P. Dalgliesh. 1996. Simulation of a legume ley farming system in northern Australia using the Agricultural Production Systems Simulator. Australian Journal of Experimental Agriculture 36:1037-1048.

Czarnecki, O., J. Yang, D.J. Weston, G.A. Tuskan, and J.G. Chen. 2013. A dual role of strigolactones in phosphate acquisition and utilization in plants. International Journal of Molecular Science 14:7681-7701. 
Figure 3

Comparison of current fixed and integrative-adaptive agricultural production systems.

Fixed management (scenarios 1 and 2)

\begin{tabular}{|l|l|}
\hline \multicolumn{1}{|c|}{ Approach } & \multicolumn{1}{c|}{ Effect } \\
\hline Cropping system & $\begin{array}{l}\text { Extended periods of } \\
\text { bare soil, increased } \\
\text { runoff, soil erosion } \\
\text { Loss of soil carbon (C) to } \\
\text { atmosphere (as GHG) }\end{array}$ \\
$\begin{array}{l}\text { Monocultures of non-nitrogen } \\
\text { (N)-fixing plants } \\
\text { High volume/cost fertilizer, } \\
\text { herbicide, pesticide inputs }\end{array}$ & $\begin{array}{l}\text { Decline in soil N/organic C, } \\
\text { microbial diversity, } \\
\text { and fungal diversity } \\
\text { Loss of excess N to water } \\
\text { resources and atmosphere } \\
\text { as (GHG) }\end{array}$ \\
\hline
\end{tabular}

-

\section{Grazing system}

Continuous grazing, no post-grazing recovery

Fire suppression policies

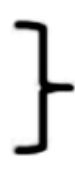

Degraded soil function, reduced ground cover Increased unpalatable plants, woody plant expansion
Adaptive management (scenarios 3 through 5)

\begin{tabular}{|l|l|}
\hline \multicolumn{1}{|c|}{ Approach } & \multicolumn{1}{c|}{ Effect } \\
\hline \multicolumn{1}{|c|}{ Integrated cropping and grazing system } \\
Minimal or zero-till cropping \\
$\begin{array}{l}\text { Multi-crop rotations include } \\
\text { N-fixing plants and cover crops } \\
\begin{array}{l}\text { Targeted micro-nutrient } \\
\text { fertilizer inputs only } \\
\text { High intensity regenerative } \\
\text { grazing, regrowth-rate related } \\
\text { recovery times } \\
\text { Improved grazing with } \\
\text { periodic fire or targeted } \\
\text { treatment of woody } \\
\text { plant expansion } \\
\text { and soil erosion }\end{array}\end{array}$ \\
$\begin{array}{l}\text { Build up in soil N/organic } \\
\text { C, microbial diversity, } \\
\text { and fungal diversity }\end{array}$ \\
$\begin{array}{l}\text { Higher C sequestration, } \\
\text { improved soil structure, } \\
\text { increased nutrient cycling, } \\
\text { improved plant species, } \\
\text { and soil microbial and } \\
\text { fungal function }\end{array}$ \\
\end{tabular}

Daley, C.A., A. Abbott, P.S. Doyle, G.A. Nader, and S. Larson. 2010. A review of fatty acid profiles and antioxidant content in grass-fed and grain-fed beef. Nutrition Journal 9:1-12.

Delgado, J.A., P.M., Groffman, M.A. Nearing, T. Goddard, D. Reicosky, R. Lal, N.R. Kitchen, C.W. Rice, D. Towery, and P. Salon. 2011. Conservation practices to mitigate and adapt to climate change. Journal of Soil and Water Conservation 66:118A-129A, doi:10.2489/ jswc.66.4.118A

DeRamus, H.A., T.C. Clement, D.D. Giampola, and P.C Dickison. 2003. Methane emissions of beef cattle on forages: efficiency of grazing management systems. Journal of Environmental Quality 32:269-277.

Follett, R.F., and D.A. Reed. 2010. Soil carbon sequestration in grazinglands: Societal benefits and policy implications. Range Ecology and Management 63:4-15.

Frank, D.A., and S.J. McNaughton. 2002. The ecology of the Earth's grazing ecosystems. BioScience 48:513-521.

Gattinger, A., A. Muller, M. Haeni, C. Skinner, A. Fliessbach, N. Buchmann, P. Mäder, M. Stolze, P. Smith, N. El-Hage Scialabba, and U. Niggli. 2012. Enhanced top soil carbon stocks under organic farming. Proceedings of the National Academy of Sciences 109:18226-18231.

Gerrish,J. 2004. Management-intensive grazing:The grassroots of grass farming. Ridgeland, MS: Green Park Press.

Hatfield, J.L., and R.T.Venterea. 2014. Enhanced efficiency fertilizers: A multi-site comparison of the effects on nitrous oxide emissions and agronomic performance. Agronomy Journal 106:679-680.

Hatfield, J.L., and C.L. Walthall. 2014. Soil biological fertility: Foundation for the next revolution in agriculture? Communications in Soil Science and Plant Analysis 46:753-762.

Herrero, M., and P.K. Thornton. 2013. Livestock and global change: Emerging issues for sustainable food systems. Proceedings of the National Academy of Sciences 110:20878-20881.

IPCC (Intergovernmental Panel on Climate Change) 2013. Climate Change 2013: The Physical Science Basis. Contribution of Working Group I to the Fifth Assessment Report of the Intergovernmental Panel on Climate Change, eds. T.F.Stocker, et al. Cambridge and New York: Cambridge University Press.

Jamali, H., S.J. Livesley, S.P. Grover, T.Z. Dawes, L.B. Hutley, G.D. Cook, and S.K. Arndt. The importance of termites to the $\mathrm{CH}_{4}$ balance of a tropical savanna woodland of northern Australia. Ecosystems 14:698-709.

Janzen, H.H. 2010. What place for livestock on a re-greening earth? Animal Feed Science and Technology 166-167:783-796.

Khan, S.A., R.L. Mulvaney, T.R. Ellsworth, and C.W. Boast. 2007. The myth of nitrogen fertilization for soil carbon sequestration. Journal of Environmental Quality $36: 1821-1832$
Kimble, J., C.W. Rice, D. Reed, S. Mooney, R.F. Follett, and R. Lal. 2007. Soil Carbon Management: Economic, Environmental, and Societal Benefits. Boca Raton: CRC Press.

Lal, R. 2003. Soil erosion and the global carbon budget. Environment International 29:437-450.

Lal, R. 2004. Soil carbon sequestration impacts on global climate change and food security. Science 304:1623-1627

Leake, J.R., D. Johnson, D. Donnelly, G. Muckle, L. Boddy, and D. Read. 2004. Networks of power and influence: The role of mycorrhizal mycelium in controlling plant communities and agroecosystem functioning. Canadian Journal of Botany 82:1016-1045.

Leigh, J., A. Hodge, and A.H. Fitter. 2009. Arbuscular mycorrhizal fungi can transfer substantial amounts of nitrogen to their host plant from organic material. New Phytologist 181:99-207.

Liebig, M.A., J.R. Gross, S.L. Kronberg, R.L. Phillips, and J.D. Hanson. 2010. Grazing management contributions to net global warming potential:A long-term evaluation in the Northern Great Plains. Journal of Environmental Quality 39:799-809.

MEA (Millennium Ecosystem Assessment). 2005. Ecosystems and Human Well-being: Synthesis. Washington, DC: Island Press.

Mulvaney, R.L., S.A., Khan, and T.R. Ellsworth. 2009. Synthetic nitrogen fertilizers deplete soil nitrogen: 
A global dilemma for sustainable cereal production. Journal of Environmental Quality 38:2295-2314.

National Research Council. 2002. Riparian Areas: Functions and Strategies for Management, pp. 415. Washington, DC: National Academic Press.

O'Mara, F.P. 2011. The significance of livestock as a contributor to global greenhouse gas emissions today and in the near future. Animal Feed Science and Technology 166-167:7-15.

Pimentel, D., P. Hepperly, J. Hanson, D. Douds, and R. Seidel. 2005. Environmental, energetic and economic comparisons of organic and conventional farming systems. Bioscience 55: 573-582.

Retallack, G.J. 2013. Global cooling by grassland soils of the geological past and near future. Annual Review of Earth and Planet Sciences 41:69-86.

Ripple, W.J., P. Smith, H. Haberl, S.A. Montzka, C. McAlpine, and D.H. Boucher. 2014. Ruminants, climate change and climate policy. Nature Climate Change 4:2-5.

Teague, W.R., S.L. Dowhower, S.A. Baker, N. Haile, P.B. DeLaune, and D.M. Conover. 2011. Grazing management impacts on vegetation, soil biota and soil chemical, physical and hydrological properties in tall grass prairie. Agriculture Ecosystems and Environment 141:310-22.

Teague, W.R., F. Provenza, U.P. Kreuter, T. Steffens, and M. Barnes. 2013. Multi-paddock grazing on rangelands: Why the perceptual dichotomy between research results and rancher experience? Journal of Environmental Management 128:699-717.

Turner, R.E., and N.N. Rabalais. 2003. Linking landscape and water quality in the Mississippi River basin for 200 years. Bioscience 53:563-572.

UN FAO (Food and Agriculture Organization of the United Nations). 2011. Statistical database. http://faostat3.fao. org/faostat-gateway/go/to/download/R/RL/E.

USDA. 2012. http://usda.mannlib.cornell.edu/usda/nass/ CropProdSu//2010s/2011/CropProdSu-01-12-2011_ revision.pdf.

USEPA (US Environmental Protection Agency). 2006. Global Anthropogenic Non- $\mathrm{CO}_{2}$ Greenhouse Gas Emissions: 1990-2020. Washington, DC: USEPA, EPA 430-R-06003. http://www3.epa.gov/climatechange/Downloads/ EPAactivities/GlobalAnthroEmissionsReport.pdf.

USEPA. 2013. U.S. Greenhouse Gas Inventory Report: 19902013. Washington, DC: USEPA. http://www.epa.gov/ climatechange/ghgemissions/usinventoryreport.html.

Van der Ploeg, J.D., P.Verschuren, F.Verhoeven, and J. Pepels. 2006. Dealing with novelties: A grassland experiment reconsidered. Journal of Environmental Policy and Planning 8:199-218.
Vermeulen, S.J., B.M. Campbell, and J.S.I. Ingram. 2012. Climate change and food systems. Annual Review of Environment and Resources 37:195-222.

West, P.C., J.S. Gerber, P.M. Engstrom, N.D. Muelle, K.A. Brauman, K.M. Carlson, E.S. Cassidy, M. Johnston, G.K. MacDonald, D.K. Ray, and S. Siebert. 2014. Leverage points for improving global food security and the environment. Science 345:325-328. 